\title{
Entre ciência e história: Brasil, um jardim para a França
}

\author{
[ Between science and history: Brazil, a garden for France
}

\section{Ana Beatriz Demarchi Barel ${ }^{\mathrm{x}}$}

RESUMO - A literatura de viagens que diz respeito às relações entre França e Brasil remonta a tempos pré-coloniais, quando, ao menos no século XII, narrativas míticas circulavam na Europa e descreviam, imaginando, o território que virá a ser chamado pelos portugueses de Brasil. Realizando um recorte cronológico, dedicamo-nos ao estudo de dois viajantes franceses do século XIX, praticamente contemporâneos, Ferdinand Denis e Auguste de Saint-Hilaire. Nossa leitura, na primeira parte do artigo, se funda na aproximação entre os romances indianistas de Alencar, Iracema e, sobretudo, O guarani, e uma obra ficcional de Denis, o conto "Les machakalis”, com o intuito de destacar a representação do indígena nos dois autores. Num segundo momento, cotejamos Voyage aux sources du rio $S$. Francisco et dans la province de Goyaz, relato de viagem de Saint-Hilaire, com as obras literárias de Alencar e Denis para destacar a imagem que o botânico francês define para o Brasil e que retoma, num certo sentido, o mito fundador do país, fortemente ligado ao indígena, de um jardim verdejante. • PALAVRAS-CHAVE - Ferdinand Denis; Auguste de Saint-Hilaire; relatos de viajantes franceses. •

\begin{abstract}
The travel literature that relates to relations between France and Brazil dates back to pre-colonial times when, at least in the I2th century, mythic narratives circulated in Europe, and described, imagining, the territory that the Portuguese will call Brazil. Carrying out a chronological outline, we dedicated ourselves to the study of two Igth century French travelers, practically contemporary, Ferdinand Denis and Auguste de Saint-Hilaire. Our reading, in the first part of the article, is based on the approximation between the Indianist novels by Alencar, Iracema and, above all, O Guarani, and a fictional work by Denis, the short story "Les machakalis", in order to highlight the representation of the indigenous in the two authors. In a second moment, we compared Voyage aux sources of the $S$. Francisco river et dans la province de Goyaz, a travel account by SaintHilaire, with the literary works of Alencar and Denis in order to highlight the image that the French botanist defines for Brazil and that retakes, in a certain sense, the founding myth of the country, strongly linked to the indigenous, of a verdant garden. - KEYWORDS - Ferdinand Denis; Auguste de Saint-Hilaire; reports of French travelers.
\end{abstract}

Recebido em 20 de setembro de 2020

Aprovado em I8 de agosto de $202 \mathrm{I}$

BAREL, Ana Beatriz Demarchi. Entre ciência e história: Brasil, um jardim para a França. Revista do Instituto de Estudos Brasileiros, Brasil, n. 80, p. I66-I85, dez. 202I.

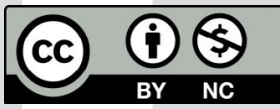

DOI: https://doi.org/Io.II606/issn.23I6-90IX.vIi8opI66-I85

I Universidade Estadual de Goiás (UEG, Anápolis, Goiás, Brasil). 
A literatura de viagens entre França e Brasil pode ser identificada já em tempos pré-coloniais, quando, ao menos no século XII, narrativas míticas circulavam pelo continente europeu e descreviam, imaginando, o território que virá a ser chamado pelos portugueses de Brasil: uma ilha muito verde, inicialmente localizada a oeste da Irlanda e que, após vários deslocamentos retóricos e míticos, será finalmente situada a oeste do continente africano. Sendo mencionada em relatos de viagens, a ilha será representada em inúmeros mapas, construindo uma cartografia imaginária desde ao menos a Idade Média, mas remontando às narrativas de Frei Brandão e seus seguidores, no século VI.

Ainda que esse não seja o objetivo de nosso trabalho, deixamos a seguir o trecho em língua francesa e nossa tradução livre para a língua portuguesa do momento em que São Brandão e seus companheiros chegam ao que consideram ser o Paraíso Terrestre, um jardim que foi associado no discurso historiográfico à natureza imaginária do Brasil.

Enfin, le Roi divin leur permet d'approcher du rideau de brouillard qui cerne de toutes parts le Paradis dont Adam avait été seigneur. Les gros nuages obscurcissent tout, de sorte que les héritiers d'Adam n'ont plus aucun recours : l'énorme rideau de brouillard empêche de voir à tel point que celui qui le pénètre est complètement aveuglé à moins que Dieu ne lui fournisse une vision qui lui permette de traverser le brouillard. Alors l'hôte déclara : «Il n'y a pas de temps à perdre; mettez toutes voiles dehors! » A mesure qu'ils approchent, le nuage se déchire et leur ouvre un passage étroit. Ils s'aventurent à travers le brouillard, et leur chemin s'élargit. Flanqués de part et d'autres d'énormes murailles de brouillard dense, qui s'accumule à droite et à gauche, ils mettent toute leur confiance dans leur hôte. Pendant trois jours, ils font voile en ligne droite, suivant le chemin qui s'est ouvert pour eux. Le quatrième jour, à la grande joie des pèlerins, ils sortent du nuage. Laissant le brouillard derrière eux, ils arrivent en vue $d u$ Paradis. Ils voient tout d'abord un mur qui s'élève jusque dans les nuages, un mur sans créneaux, ni chemin de ronde, ni brétèche, ni tour d'aucune sorte. Aucun des moines ne sait, à vrai dire, de quel matériau ce mur est construit, mais il est encore plus blanc que neige: c'est le Roi céleste qui l'a érigé. Il l'a fait sans le moindre effort, tout d'une pièce et sans brèche. Il est parsemé de gemmes qui projettent une grande lumière éclatante : chrysolithes de choix tachetés d'or en grande quantité; le mur flamboie, resplendissant de topazes, chrysoprases, 
hyacinthes, calcédoines, émeraudes, sardoines; en bordure, des jaspes et des améthystes luisent avec éclat; il y a aussi la jacinthe brillante, le cristal et le béryl qui se renvoient leur luminosité : c'est un artiste de grand talent qui a su monter de telles réfléchissent entre brillance de leurs reflètent à leur tour les unes dans les autres. La mer clapote contre les hautes montagnes de marbre dur qui s'étendent loin du mur; et sur cette chaîne de montagnes de marbre s'élève une autre montagne entièrement d'or pur. Au sommet de celle-ci se dresse le mur qui enclot les fleurs du Paradis. C'est ce mur, situé ainsi en position dominante, qui (s'il n'y avait pas eu Adam) aurait dû nous servir d'abri. Les moines mettent le cap directement sur l'entrée, mais il leur est très difficile de la franchir, car elle est gardée par des dragons qui brûlent de partout comme s'ils n'étaient pierreries. Elles elles la grande couleurs qui se la poignée en haut, la pointe en bas; celui qui n'en a pas peur est bien téméraire, et il n'est pas étonnant, je crois, si les moines s'effraient. La glaive se balance et tournoie; rien qu'à le voir, on a le vertige. Ni le fer, ni le roc, ni le diamant ne donnent de protection contre son tranchant. Puis les moines virent venir à leur rencontre un jeune homme d'une très grande beauté; il s'agit du messager de Dieu qui leur donne l'ordre d'accoster. Dès qu'ils sont à terre, il les accueille en les appelant chacun correctement par leur nom, puis il les embrasse avec tendresse. Il calme tous les dragons et les fait se coucher par terre en grande humilité et en paix; il fait retenir le glaive par un ange qu'il fait venir. L'entrée est dégagée, et ils entrent tous dans la gloire assurée. Le jeune homme, les précédant, leur fait visiter le Paradis. Ils voient une terre très fertile en beaux bois et en prairies. Les prés, splendides et constamment en fleurs, $y$ forment un jardin. Les fleurs sentent très bon, comme il convient à un endroit qu'habitent les saints, un lieu où les arbres et lesfleurs font les délices de ceux qui les regardent, et où les fruits et les parfums sont d'une richesse inestimable. Ni ronces, ni chardons, ni orties n'y poussent à profusion; il n'y a pas d'arbre ni d'herbe qui n'exhale une odeur suave. Les arbres sont continuellement chargés de fruits, et les fleurs toujours en plein épanouissement, sans tenir compte de la saison qui ne change pas; c'est toujours l'été, et le temps reste doux. Les fruits sont toujours mûrs sur l'arbre. Les fleurs produisent sans cesse leur semence; les bois sont toujours remplis de gibier, et toutes les rivières d'excellents poissons. Il y a des rivières où coule le lait. Cette abondance règne partout : les roselières exsudent le miel grâce à la rosée qui descend du ciel. Il n'y a pas de montagne qui ne soit d'or, pas de grosse pierre qui ne vaille un trésor. Le soleil ne cesse d'y briller de tout son éclat, aucun vent, aucun souffle ne vient remuer le moindre cheveu, aucun nuage dans le ciel ne masque la lumière du soleil. L'habitant n'y souffrira aucun malheur, il ne connaîtra aucun orage, il sera à l'abri du chaud, du froid, de l'affliction, de la faim, de la soif, de la privation. Il aura tout ce qu'il souhaite, en abondance. Il est certain de ne jamais être privé de ce qu'il désire le plus; il l'aura toujours à sa disposition. Absorbé par la contemplation de toute cette félicité, Brendan ne voit pas passer le temps; il voudrait y rester encore longtemps. Le guide le mena beaucoup plus loin encore, et lui fit voir bien d'autres choses: il lui décrivit en grands détails les délices dont jouira chacun. Il gravit un tertre aussi haut qu'un cyprès, et Brendan le suit; d'ici Brendan et ses moines ont des visions qu'ils ne parviennent pas à expliquer. Ils voient des anges et les entendent se réjouir de leur arrivée. Ils écoutent leurs grands chants mélodieux mais en viennent à ne plus les supporter : les mortels ne sont pas de nature à comprendre ou à concevoir tant de gloire. Leur jeune guide leur dit: «Faisons demi-tour! Je ne vous mènerai pas plus loin; il ne vous est pas permis de continuer, car tout cela dépasse votre entendement. Brendan, tu as pu voir le Paradis que tu as supplié Dieu de te révéler. Plus loin, il y a cent mille fois plus de gloire que tu n'as vue jusqu'ici. Pour le moment, en attendant que 
tu reviennes ici, tu n'en connaîtras pas plus. Là où tu es venu aujourd'hui en chair et en os, tu reviendras bientôt en esprit. A présent, pars; tu reviendras pour attendre le Jugement dernier ici. Fais emporter avec toi quelques- unes de ces pierres comme témoignages de consolation. » Quand le guide eut fini de parler, Brendan s'en alla, emportant des témoignages de sa visite au Paradis. Il prit congé de Dieu et des saints bien-aimés du Paradis. Le jeune homme les reconduisit: quand ils furent tous embarqués dans le bateau, il leur donna sa bénédiction. Ils eurent vite fait de hisser la voile. Leur hôte pieux resta au Paradis où il avait sa demeure légitime. (SHORT; MERRILEES, I999, p. II4-I24).

[Finalmente, o Rei divino permite que eles se aproximem da cortina de névoa que envolve por todos os lados o Paraíso do qual Adão havia sido senhor. As grandes nuvens obscurecem tudo, para que os herdeiros de Adão não tenham mais recurso: a enorme cortina de névoa impede ver tanto que quem nela entra fica completamente cego, a menos que Deus lhe dê uma visão... que lhe permita passar pela névoa. Então o anfitrião disse: "Não há tempo a perder; ponha todas as velas para fora! À medida que se aproximam, a nuvem se rasga e abre uma passagem estreita para eles. Eles se aventuram através da névoa, e seu caminho se alarga. Flanqueados de ambos os lados por enormes paredes de denso nevoeiro, que se acumula à direita e à esquerda, depositam toda a confiança no seu anfitrião. Durante três dias navegam em linha reta, seguindo o caminho que se abriu para eles. No quarto dia, para grande alegria dos peregrinos, eles emergem das nuvens. Deixando a névoa para trás, eles podem avistar o céu. Em primeiro lugar, eles veem uma parede que se eleva até as nuvens, uma parede sem ameia, muralha, brecha ou torre de qualquer tipo. Nenhum dos monges realmente sabe de que material essa parede é feita, mas ela ainda é mais branca do que a neve: foi o Rei Celestial que a ergueu. Ele fez isso sem esforço, inteiro e sem falhas. É cravejado de gemas que projetam uma grande luz brilhante: crisólitos de escolha salpicados de ouro em grandes quantidades; a parede resplandece, resplandecente com topázios, crisoprases, jacintos, calcedônias, esmeraldas, sardônias; na fronteira, jaspes e ametistas brilham intensamente; há também o jacinto brilhante, o cristal e o berilo, que refletem sua luminosidade: é um artista muito talentoso que soube montar tais reflexos entre o brilho de seu reflexo um no outro. O mar bate nas altas montanhas de mármore duro que se estendem longe da parede; e nessa cadeia de montanhas de mármore ergue-se outra montanha inteiramente de ouro puro. No topo fica a parede que envolve as flores do Paraíso. É essa parede, assim situada em posição dominante, que (se não fosse por Adão) deveria ter servido como nosso abrigo. Os monges vão direto para a entrada, mas é muito difícil para eles cruzá-la, pois é guardada por dragões que queimam por toda parte como se fossem pedras preciosas. Eles têm as grandes cores que são a alça na parte superior, a ponta na parte inferior; aquele que não tem medo é muito imprudente, e não é surpreendente, creio eu, que os monges estejam assustados. A espada balança e gira; só de ver você fica tonto. Nem o ferro, nem a rocha, nem o diamante protegem contra o seu gume. Então os monges viram um jovem de grande beleza vir ao seu encontro; é o mensageiro de Deus que lhes dá a ordem de atracar. Assim que eles estão no chão, ele os saúda chamando cada um deles corretamente pelo nome, depois os beija ternamente. Ele acalma todos os dragões e os faz deitar no chão em grande humildade e em paz; ele tem a espada retida por um anjo 
a quem ele chama. A entrada é desimpedida e todos eles entram na glória garantida. $\mathrm{O}$ jovem, precedendo-os, mostra-lhes o paraíso. Eles veem uma terra muito fértil com belos bosques e prados. Os prados, esplêndidos e em constante floração, formam um jardim. As flores cheiram muito bem, como convém a um lugar onde moram santos, um lugar onde as árvores e as flores fazem as delícias de quem as contempla, e onde os frutos e os perfumes são de uma riqueza inestimável. Nem amoreiras, cardos ou urtigas crescem lá em profusão; não há árvore ou grama que exale um perfume doce. As árvores estão continuamente carregadas de frutos e as flores sempre em plena floração, independentemente da estação que não muda; ainda é verão e o clima ainda é ameno. Os frutos ainda estão maduros na árvore. As flores produzem constantemente suas sementes; os bosques estão sempre cheios de caça e todos os rios com peixes excelentes. Existem rios por onde corre o leite. Essa abundância reina em todos os lugares: os canaviais exalam mel graças ao orvalho que desce do céu. Não há montanha que não seja ouro, nem uma grande pedra que não valha um tesouro. $\mathrm{O}$ sol nunca cessa de brilhar ali com todo o seu brilho, nenhum vento, nenhuma respiração vem para agitar o menor cabelo, nenhuma nuvem no céu obscurece a luz do sol. $\mathrm{O}$ habitante não sofrerá nenhum infortúnio, não experimentará nenhuma tempestade, estará protegido do calor, do frio, das aflições, da fome, da sede, da privação. Ele terá tudo o que deseja, em abundância. Ele tem certeza de que nunca será privado do que mais deseja; ele sempre o terá à sua disposição. Absorto na contemplação de toda essa bem-aventurança, Brendan não vê o tempo passar; ele gostaria de ficar lá por muito tempo. O guia levou-o ainda mais longe e mostrou-lhe muitas outras coisas: descreveu-lhe detalhadamente as delícias de que cada um desfrutará. Ele sobe um monte tão alto quanto um cipreste, e Brendan o segue; daqui, Brendan e seus monges têm visões que não conseguem explicar. Eles veem anjos e os ouvem regozijando-se com sua chegada. Eles ouvem suas grandes canções melodiosas, mas não as suportam mais: os mortais não são de natureza a compreender ou conceber tanta glória. $\mathrm{O}$ jovem guia disse-lhes: "Vamos dar a volta! Não vou levá-lo adiante; você não tem permissão para continuar, pois está tudo além da sua compreensão. Brendan, você tem que ver o céu que implorou a Deus que lhe revelasse. Além, há cem mil vezes mais glória do que você viu até agora. Por enquanto, até você voltar aqui, você não saberá mais. Para onde você veio hoje em carne e sangue, você logo retornará em espírito. Agora vá; você voltará para esperar o Juízo Final aqui. Leve algumas dessas pedras como testemunhos de consolo". Quando o guia terminou de falar, Brendan saiu, levando testemunhos de sua visita ao céu. Ele se despediu de Deus e dos amados santos no céu. O jovem os conduziu de volta: quando todos entraram no barco, ele lhes deu sua bênção. Eles içaram a vela rapidamente. Seu piedoso anfitrião permaneceu no Paraíso, onde tinha seu legítimo lar. $\left.{ }^{2}\right]$

O tema, que já abordamos em trabalho anterior (BAREL, 2006)3, está ligado

2 Indicaremos, logo após os trechos citados em língua francesa, a tradução livre de nossa autoria.

3 Trata-se de artigo que integra Les Cahiers du CREPAL n. I2, publicação do Centre de recherches sur les pays lusophones de l'Université Paris III Sorbonne Nouvelle, cujo tema central era o conceito de excesso na literatura. 
ao que Sérgio Buarque de Holanda discute, confrontando com documentação historiográfica, sobre as visões do Paraíso e os motivos edênicos no descobrimento e colonização do Brasil. A viagem de São Brandão seria, portanto, uma antecipação ou coincidência em relação ao nome, bem como à natureza imaginária do Brasil como Paraíso Terrestre.

Esse universo, permeado pela mitologia e registrado pela história, será absorvido pela literatura, que o representará nas relações entre os dois países, suas sociedades e os espaços em que se deslocam. Forjado em sua origem pelo objetivo do viajante que o escreve, o relato de viagem será portador de diferentes conjuntos de informações, apresentando-as sob um amplo leque de tipos de textos, indo de relatórios científicos a diários íntimos, balancetes comerciais e documentos diplomáticos, catálogos científicos, obras de ficção, poemas, cartas, para evocarmos apenas alguns. A complexidade e a riqueza desse material são facilmente confirmadas pela multiplicidade das áreas de conhecimento que se dedicam à temática e aos diferentes campos das ciências que tratam do assunto. A bibliografia sobre os relatos de viagens aproxima a história, a biologia, a botânica, a literatura, a antropologia, a geografia, a diplomacia, as ciências políticas, e tantos outros domínios.

Nesse sentido, realizando um recorte cronológico para delimitar nosso objeto de pesquisa, dedicamo-nos ao estudo de dois viajantes franceses do século XIX, praticamente contemporâneos, Ferdinand Denis e Auguste de Saint-Hilaire. Nossa escolha se justifica pelo fato de que, apesar de terem vivido no Brasil praticamente na mesma época, seus escritos divergem em seus objetivos, em suas motivações e, logo, em sua natureza, tanto estética quanto teórica. Interessa-nos verificar a representação que ambos fizeram do Brasil, em que medida o país é apreendido por seu olhar. Ademais, os itinerários percorridos por Denis e Saint-Hilaire são distintos, ainda que ambos tenham conhecido, em parte, as mesmas regiões. Já antecipando uma qualidade importante da obra de Saint-Hilaire, os escritos do botânico despertam ainda mais interesse uma vez que ele percorre regiões e chega a destinos que poucos viajantes incluíram em seus projetos.

Se Ferdinand Denis é meu já velho conhecido, estando em minhas leituras há cerca de vinte anos, indicando-me caminhos, apontando-me portas a abrir, documentos a desempoeirar em arquivos insuspeitados, outras descobertas virão, ao longo desse percurso que farei com meu novo companheiro de viagens, Auguste de Saint-Hilaire, esse botânico de alma sensível que nos legou um precioso, denso e esperançoso retrato do Brasil, a quem recentemente comecei a me dedicar e a conhecer.

Ferdinand Denis, viajante francês que esteve no Brasil entre I8I6 e I8I9, percorrerá parte dos estados da Bahia, do Rio de Janeiro e de Minas Gerais. Como resultado dessa estada brasileira, ele levará na bagagem, no retorno à França, menos do que imaginou ao partir de Paris, e mais do que poderia crer, de volta para casa. Inicialmente, conservador da Bibliothèque Saint-Geneviève, Denis chegará ao cargo de diretor da instituição, legando a ela um acervo importante do qual fazem parte obras que dizem 
respeito ao Brasil e aos anos em que nele viveu, em busca de fortuna para a família e de um lugar na diplomacia da França.

Estando no Brasil às vésperas da Independência, Denis percebe as inquietações do momento histórico que vivia o país e, atento a esse estado de coisas, de volta à França, publica várias obras sobre a natureza, a flora, a fauna e os habitantes do Brasil, como Le Brésil, ou Histoire, mœurs, usages et coutumes des habitans de ce royaume, de I822, e Scènes de la nature sous les tropiques, et de leur influence sur la poésie, de I824, além de ser o pioneiro nos estudos historiográficos da literatura brasileira, não mais entendida como um ramo exótico das letras portuguesas e, sim, como uma literatura independente da de Portugal.

Será assim que sairá à luz seu Résumé de l'histoire littéraire du Portugal suivi du résumé de l'histoire littéraire du Brésil, em I826, consagrando Ferdinand Denis como o precursor dos estudos historiográficos literários brasileiros e como o autor de nossa primeira história literária.

Agindo em duas frentes, o jovem viajante, que deixaria seu nome nos estudos franco-brasileiros, também produz um texto literário, "Les machakalis", publicado em I824, no qual exemplifica como deveriam ser nossas obras, quais temas deveriam nos importar e como era fundamental para nossa independência literária, indissociável da política, olharmos para dentro do país, abandonando o modelo neoclássico, as ninfas e musas do Parnaso.

A novela de Ferdinand Denis, ao alçar o índio e a natureza brasileiros a tema digno de ser tratado pela literatura e propor que de fato ambos ilustrama identidade nacional da nação recém-independente, marca um ponto de virada na historiografia literária brasileira, inspirando os escritores do chamado Primeiro Romantismo. Dentre eles, José de Alencar.

É, portanto, relevante, a leitura de "Les machakalis" para observarmos a estrutura do texto, classificado como novela ou conto longo, e os preceitos ali contidos sobre a formação de nossa identidade literária. Nele, observamos, por exemplo, um capítulo de abertura que lembra a do romance Iracema. O narrador nos revela como teve acesso à história que será contada e que remete ao mito e às narrativas orais. Essa é uma estratégia importante de valorização do material de origem indígena, ou seja, das lendas, do material folclórico de fundo popular no qual se forja a cultura brasileira, alçando-o ao status de tema digno de ser incluído no cânone literário. Se em Iracema o narrador retoma o processo de transmissão das histórias do povo, assumindo nesse momento, o lugar do contador - "Uma história que me contaram nas lindas várzeas onde nasci, à calada da noite, quando a Lua passeava no céu argenteando os campos, e a brisa rugitava nos palmares" (ALENCAR, s. d, p. 20) -, em "Les machakalis" (DENIS, I824, p. I30) o narrador afirma ter tido conhecimento da trama numa viagem, através de um jovem chefe indígena: "je veux me borner à rapporter l'histoire qu'un jeune chef raconta autrefois dans ces pays lointains" ("eu quero me limitar a relatar a história que um jovem chefe recontara outrora nessas terras distantes”.

Em O guarani essa estrutura-moldura de evocação mítica não aparece e, sim, um longo introito de dois capítulos intitulados "Cenário" e "Lealdade”, que prepara, pela recuperação do contexto histórico em que se desenrolará o enredo, a introdução dos personagens do romance. Assim, Alencar diversifica as estruturas das obras de 
fundo histórico pelo uso de elementos que legitimam o relato, ou pela validade do mito, compartilhado pelas nações indígenas e com valor de verdade simbólica, ou pela inserção de fatos históricos e, portanto, com valor de verdade documental para a cultura do Ocidente e letrada da qual faz parte a do novo país, agora independente.

Essas estratégias consolidam, pela literatura, o discurso histórico que, ao mesmo tempo, lhe fornece estofo e matéria.

Apesar de haver vários pontos em comum entre O guarani e "Les machakalis", como a indicação do contraste já então perceptível entre campo/selva/mato e cidade, a referência à natureza de forma idílica, a tematização dos conflitos e negociações entre índios e brancos, e outros tópicos que poderíamos aqui elencar se este fosse o objetivo deste trabalho, há algumas diferenças que são importantes para a construção de uma identidade literária no Romantismo e para a representação do herói nacional em vias de consolidação, o indígena.

O texto de Ferdinand Denis, aliás, contém elementos já bastante matizados de Realismo, pois, ainda que o tema central seja uma história de amor, denuncia a situação dos povos indígenas no momento mesmo da colonização. Há vários exemplos disso, um deles é o do diálogo entre pai e filho, quando Koumourahy avisa os guerreiros da tribo que partirá em busca do tesouro necessário em troca do casamento com Helena. Nele, o velho guerreiro denuncia os abusos da colonização e a cupidez dos portugueses.

Pourquoi, jeune chef, te laisses-tu abuser par un vain espoir, et qu'as-tu besoin d'aller rassembler des trésors inutiles? ne connais-tu pas la perfidie de l'étranger? Si tu l'ignores, les vieillards n'en ont point perdu le souvenir et de longs regrets sont tout ce qu'ils ont retiré de leur ancienne confiance. Tu n'épouseras pas Héléna, te dis-je, on se réjouira de ton infortune, et tes richesses ne feront que des ingrats. Le sort avait accordé aux Portugais le bord de la mer: que viennent-ils chercher dans nos forêts? Que veulent-ils de nous? Que demandent-ils enfin ? D'autres t'indiqueront les lieux où tu peux trouver la mort: mes conseils ne te seront jamais funestes; ;'ai toujours méprisé les feintes caresses des Européens. (DENIS, I824, p. 455).

[Por que, jovem chefe, você se deixa enganar por uma vã esperança e por que precisa ir acumular tesouros desnecessários? Você não conhece a perfídia do estrangeiro? Se você a ignora, os velhos não perderam a memória disso, e longos arrependimentos foi tudo o que eles retiraram de sua antiga confiança. Você não se casará com Helena, eu lhe digo, se alegrarão com sua desgraça, e suas riquezas farão apenas ingratos. $O$ destino dera aos portugueses a beira do mar: o que eles procuram nas nossas florestas? $\mathrm{O}$ que eles querem de nós? $O$ que eles pedem enfim? Outros lhe indicarão os lugares onde você pode encontrar a morte: meus conselhos nunca lhe serão funestos. Eu sempre desprezei as carícias fingidas dos europeus].

A viagem do protagonista pelo interior das terras brasileiras em busca do dote para obter Helena é o pretexto para evidenciar a matéria autêntica, inédita e essencialmente nacional que deveria orientar a produção literária de nossos jovens escritores românticos. A viagem pelo território brasileiro permite ao leitor conhecer as diferentes nações indígenas, a relação que tinham entre si, seu conhecimento 
da paisagem, da riqueza das terras e os diversos lugares geográficos existentes no percurso. É assim que os Goyazes, os Cayapos, os Ararys, os Patachos surgem pelo caminho, criando os obstáculos imprescindíveis para a valorização das características nobres do jovem herói Koumourahy. Destemido, ele enfrenta todos os inimigos, todas as dificuldades para cumprir sua missão e obter seu prêmio.

Nas duas obras literárias há uma aparente história de amor, sendo necessário, aqui, explicitar o que as diferencia e o que as aproxima. Em ambos os textos, o que se chama de amor não é exatamente aquele em que há a atração física e o sentimento de bem-querer idealizado e sublime. O sentimento que liga os protagonistas, tanto em Alencar como em Denis, é, sob a aparência de amor, o poder. Porém, se em "Les machakalis" ele é descrito mais como paixão e atração, em O guarani, ele é tratado como platônico, idealizado, espiritual, como devoção.

Em “Les machakalis” o maior obstáculo para a consumação desse amor é a religião, e Koumourahy abre mão sem grandes resistências de sua fé a fim de obter Helena. Move céus e terras, literalmente, para cumprir sua parte no trato que faz com o ouvidor, seu pai, trazendo para a cidade dos portugueses as riquezas que prometera e que aqueles cobiçavam. É traído, não recebendo Helena como contrapartida a seu esforço.

“Koumourahy, me dit-elle, si tu veux conserver l'amitié, garde- toi de me parler d'amour”. Mais j'étais un insensé que la raison ne pouvait convaincre; je n'avais plus le pouvoir de lui obéir. Viens visiter ma tribu, luis disais-je quelquefois, mes indiens te regardent comme une divinité bienfaisante; si tu voulais que je devinsse ton époux, je rassemblerais d'immenses richesses, et tu commanderais à tout ce que m'entoure; moi-même je n'aurais point d'autre volonté que la tienne. Alors elle s'éloignait comme si ma témérité l'eût effrayée; ou bien elle me disait: "je dois habiter les villes; ce bonheur que l'on goûte dans le désert n'est pas fait pour moi; tu ne me verras jamais dans ta cabane". (DENIS, I824, p. 453).

[“Koumourahy”, ela me disse, "se você quiser manter a amizade, não me fale de amor ”. Mas fui um insensato que a razão não podia convencer; eu não tinha mais o poder de obedecê-la. Venha visitar minha tribo, dizia-lhe algumas vezes, meus índios o consideram uma divindade benéfica; se você quisesse que eu me tornasse seu marido, eu acumularia riquezas imensas e você governaria tudo ao meu redor; eu mesmo não teria outra vontade senão a sua. Então ela se afastou como se minha ousadia a tivesse assustado; ou então ela me dizia: "Devo viver nas cidades; essa felicidade que se prova no deserto não é feita para mim; você nunca vai me ver em sua cabana”.]

No romance de Alencar, o que impede a existência do amor é o próprio objetivo do projeto do autor não em escrever um romance de amor, mas que forneça ao Brasil o herói de que necessita. Peri, muito mais do que um homem apaixonado, é a encarnação das qualidades morais do herói-guerreiro, do herói-santo, do herói-armado cavaleiro. Dessa forma, para ele o amor carnal não pode ser um fim, o amor carnal não é sua prioridade, mas a prova, a cada ato, a confirmação de que ele é um guardião e um receptáculo dos valores morais imprescindíveis para o herói que resume a nobreza de caráter de seu povo. Renegar sua fé torna-se então inegociável em termos concretos, objetivos e palpáveis, só se consumando essa descrença quando a troca se faz com 
vistas à salvação da vida de Cecília, ou seja, o bem maior e imaterial. Mais do que obras sobre o encontro de raças, sobre relações étnicas, os textos tratam do encontro de colonizador e colonizado e da questão religiosa, do peso desse componente importante da identidade cultural e de sua representação na obra literária. Os obstáculos - ainda que para objetivos diferentes nas duas tramas - não existem entre Cecília e Peri nem entre Helena e Koumourahy por serem elas, brancas, e eles, índios. O narrador, em $O$ guarani, de fato, desde o começo do romance, deixa tácito que o sentimento que se tece entre Cecília e Peri não é, de forma alguma, amor, mas submissão.

Assim o amor se transformava tão completamente nessas organizações, que apresentava três sentimentos bem distintos; um era uma loucura, o outro uma paixão, o último uma religião.

Loredano desejava; Álvaro amava; Peri adorava. O aventureiro daria a vida para gozar; o cavalheiro arrostaria a morte, para merecer um olhar; o selvagem se mataria, se preciso fosse, só para fazer Cecília sorrir. (ALENCAR, I992, p. 52).

Há, entre a moça branca e o índio, uma relação assimétrica impossível de ser equilibrada, e isso se deve não ao fato de ela ser branca e ele, índio, mas porque o amor entre eles é de outra natureza, é platônico. Peri não ama Cecília, nem ela o ama; portanto, a questão da raça é secundária para o aspecto amoroso da história. A incompreensão entre a forma de entender a realidade entre eles se estabelece quando vem à tona a negociação da questão religiosa. O amor de Peri por Cecília é de ordem espiritual. Evidentemente, por se tratar de personagens idealizados, de heróis, a devoção e a sinceridade na profissão de fé de cada um são incontestáveis, sendo esse o elemento ficcional que cria o conflito e lhe dá intensidade, uma vez que renunciar à sua religião torna-se um dilema de dimensão extrema. Para Peri, porém, contrariamente a Koumourahy, abrir mão da religião repercute não apenas numa posição pessoal, mas também envia a um elo com o grupo, com o coletivo. Essa é a razão, aliás, de o herói ser tratado dessa forma pelos textos, pois o que está em jogo é justamente a formação de um grupo maior, de um coletivo maior, de uma família maior, a Nação. O que está sendo decidido então é qual identidade nacional vamos escolher para o grupo e quais os passos a serem seguidos durante todo o processo de consolidação dessa identidade. Se para Peri o que prevalece é sua identidade, e isso inclui sua religião e um pacto tácito com a tribo, para Koumourahy, ao contrário, há a rejeição da identidade indígena e de seus valores. Ele rompe com a tribo, adota os valores dos brancos e é traído. Se pensarmos na época da escritura da novela denisiana, o texto se configura como uma denúncia das relações entre colonizadores e colonizados, vaticinando o futuro da história dos povos indígenas, a destruição de sua cultura, a aculturação e a negação das origens indígenas por seus descendentes. Nesse sentido, "Les machakalis" é um texto que prenuncia a estética realista, além de antecipar a própria história do Brasil.

Essa escolha estética remete a uma questão teórica importante, pois os conselhos de Ferdinand Denis, em sua obra historiográfica, para nos afastarmos dos temas europeus e para privilegiarmos a realidade brasileira, não coincidem totalmente 
com o projeto romântico dos escritores brasileiros. Se para Denis era importante construir o texto literário a partir de elementos da flora, da fauna e dos habitantes brasileiros, os índios - o que os primeiros românticos fizeram -, também fazia parte do programa denisiano mostrar a verdade dos fatos, com as traições dos europeus e a decepção dos nativos.

Koumourahy, me dit le vieillard dont la sagesse avait toujours voulu me préserver de mes projets insensés, je n'entreprendrai pas de te consoler, carce ne sont pas de vains mots qui font taire la douleur ; mais écoute un instant mes conseils. Que le courage renaisse dans ton coeur, et tu l'éloigneras des étrangers, tu fuiras avec tes indiens les lieux qu'ils habitent. N'as-tu pas vu quelquefois un oiseau de nos forêts retourner dans son nid désert? Il y recherchait, mon fils, le bonheur qu' il y avait goûté dans d'autres temps. Crois-moi, va revoir nos anciennes forêts. (DENIS, I824, p. 462).

[Koumourahy, disse-me o velho cuja sabedoria sempre quis me proteger de meus projetos tolos, não vou empenhar em consolá-lo, porque não são as palavras vãs que conseguem calar a dor; mas ouça meu conselho por um momento. Que a coragem renasça em seu coração, e você o afastará dos estrangeiros, você fugirá com seus índios dos lugares onde habitam. Você nunca viu um pássaro de nossas florestas às vezes retornar ao seu ninho deserto? Ele procurava ali, meu filho, a felicidade que ele provara noutros tempos. Acredite em mim, vá ver nossas florestas antigas novamente.]

O guarani e "Les machakalis" trazem para a literatura os meandros do processo histórico de fundação da nação brasileira e por que meios se construiu uma identidade nacional, tanto na literatura e nas artes como no discurso político.

Em 1857, grande parte das nações indígenas que haviam entrado em contato com os portugueses já havia sido ou dizimada ou tinha se confinado, partindo para o interior do território. Os conflitos com os índios são já conhecidos, e as alianças entre as nações indígenas e os europeus, frequentes. Peri representa a possibilidade de ser índio, se relacionar com os portugueses e manter sua identidade, e isso graças a uma boa dose de idealização, segundo as palavras de Alencar, em sua carta ao amigo Jaguaribe: "N'O guarani, o selvagem é um ideal, que o escritor intenta poetizar, despindo-o da crosta grosseira de que o envolveram os cronistas, e arrancando-o ao ridículo que sobre ele projetam os restos embrutecidos da quase extinta raça" (ALENCAR, I990, p. 6I).

Se em $O$ guarani Peri recusa por mais de uma vez sua conversão, termina por aceitá-la não porque esse seria o único caminho de ter Cecília, mas porque Dom Antônio de Mariz, diante da morte irrefutável, precisa confiar a vida da filha a um par, a um igual, a um cristão. Ele sagra Peri cavaleiro, e o converte, para poder entregar-lhe a vida de Cecília, que agora estaria só e órfã. O fim do romance, em princípio, parece predizer a fundação da nação brasileira pelo casal. O que reitera que a conversão do índio se torna necessária para que o pagão possa ser elevado ao patamar de confiável a receber uma vida cristã. 
No mesmo ano de I8I6, desembarcava no Brasil outro francês, Auguste-FrançoisCésar Prouvençal de Saint-Hilaire, nascido em Orléans em 4 de outubro de I779, filho de um oficial da realeza, de família pertencente à nobreza. Saint-Hilaire ficará no Brasil entre I8I6 e I822, sendo, portanto, contemporâneo de Ferdinand Denis. Saint-Hilaire concentra suas viagens entre o Centro e o Sul do país, conhecendo Rio de Janeiro, Espírito Santo, Minas Gerais, Goiás, São Paulo, Santa Catarina, Rio Grande do Sul, até chegar ao Uruguai, visitando o que restava das antigas missões jesuíticas da margem esquerda do Uruguai.

Viaja ao Brasil contratado pelo Duc de Luxembourg, Charles Emmanuel Sigismond de Montmorency-Luxembourg, então embaixador da França em Portugal, e que organizará uma expedição ao Brasil financiada por Luís XVIII.

I8I6 é um ano agitado para as relações entre Brasil e França, e Saint-Hilaire, então professor do Museu de História Natural de Paris, integra uma expedição, também de caráter político, que pretende resolver os conflitos de fronteira na Guiana Francesa. Nesse mesmo ano, dessa vez no Rio de Janeiro, desembarcaria outra expedição francesa, que se tornaria célebre na historiografia das relações franco-brasileiras, a Missão Francesa de I8I6, capitaneada pelos Taunay - Auguste-Marie, Nicolas-Antoine, Aimé-Adrien -, por Jean-Baptiste Debret e pelo encarregado da Missão, Joachim Lebreton. Em I822 Saint-Hilaire volta definitivamente à França. Estava doente e vai se no Sul, em Montpellier, aproveitando para organizar sua obra. Em I834, torna-se membro da Academia de Ciências da Prússia e, nesse mesmo ano, recebe a Ordem Portuguesa de Cristo. Auguste de Saint-Hilaire falecerá em Orléans, sua cidade natal, em 3 de setembro de I853.

Anteposta ao Prefácio ao Tomo Primeiro do Voyage dans les provinces de Rio de Janeiro et de Minas Geraes, que integra a vasta obra Voyage dans l'intérieur du Brésil, composta de quatro partes, divididas em oito tomos e publicada entre I830 e I85I, Auguste de Saint-Hilaire explicita, na dedicatória a "Monsieur Le Duc de Luxembourg, Capitaine des Gardes, Pair de France, Etc. Etc.”, os objetivos de sua viagem, reiterando seus agradecimentos àquele de quem se reconhece "votre très humble et très-obéissant serviteur" (SAINT-HILAIRE, I847, s. p.). Essas expressões, que, para além de se definirem como fórmulas de politesse e partes imprescindíveis do protocolo, aqui, de fato, se revelam a tradução do cumprimento do projeto científico levado a cabo pelo viajante. Na dedicatória, o cientista destaca que a missão de que fora incumbido tinha como finalidade maior levar aos europeus notícias e informações a respeito de uma região desconhecida para que com ela pudessem estreitar os laços, além de contribuir para o progresso da ciência. Enviado para resolver uma questão diplomática na Guiana Francesa, o Duc de Luxembourg teria acrescentado a sua expedição uma finalidade científica, para a qual é designado nosso viajante.

Si donc j'ai pu parvenir à faire mieux connaître une contrée que la nature a comblée de ses bienfaits, si je puis inspirer à mes compatriotes le désir d'avoir avec les Brésiliens des rapports plus intimes, si mes travaux ont contribué en quelque chose aux progrès de la science, c'est à vous, monsieur le Duc, que je suis redevable d'un tel bonheur... (SAINT-HILAIRE, I847, s. p.). 
[Portanto, se eu puder conseguir tornar conhecido um país que a natureza cobriu de seus benefícios, se puder inspirar nos meus compatriotas o desejo de ter relações mais íntimas com os brasileiros, se meu trabalho tiver contribuído em algo para o progresso da ciência, é com você, Senhor Duque, que estarei em dívida por tamanha felicidade...].

Ainda que o viajante declarasse que seu objetivo principal era o de catalogar e analisar diferentes espécies de plantas brasileiras e que resultaria em sua obra mais conhecida, a Flora Brasiliae Meridionalis,

L'examen des productions végétales du Brésil était sans doute le premier but de mon voyage; cependant je n'ai rien négligé pour recueillir les faits qui peuvent, sous d'autres rapports, donner une idée juste d'une contrée aussi intéressante. Je ne me suis point borné à suivre des chemins fréquentés, je me suis enfoncé dans les lieux les plus déserts, et j'ai étudié les tribus indigènes. Favorisé par les autorités locales, accueilli partout avec l'hospitalité la plus généreuse, j'ai pu voir tout ce qu'il y avait de remarquable, et réunir les renseignements précieux. (SAINT-HILAIRE, I847, p. VIII).

[Examinar a produção vegetal do Brasil foi, sem dúvida, o primeiro objetivo da minha viagem; entretanto, não negligenciei nada para recolher os fatos que podem, sob outros aspectos, dar uma ideia correta de um país tão interessante. Não me limitei de forma alguma a seguir caminhos conhecidos, penetrei nos lugares mais desertos e estudei as tribos indígenas. Favorecido pelas autoridades locais, recebido em todos os lugares com a mais generosa hospitalidade, pude ver tudo o que havia de notável e reunir informações preciosas.]

constata-se que seus escritos ultrapassam em muito o trabalho minucioso da descrição botânica. A obra de Saint-Hilaire constitui de fato um material precioso sobre a civilização do Brasil, informando sobre a paisagem, a flora, a fauna, as diversas nações indígenas dos diferentes territórios visitados, a organização política, a cobrança dos impostos, a extração do ouro, a relação dos brancos com os escravos e os indígenas, a moral, a educação, a política, enfim, um quadro bastante preciso do país naquele momento histórico.

Vale lembrar que, apesar de Voyage dans l'intérieur du Brésil ter sido escrito entre I8I6 e I822, a obra será publicada muito tempo depois, sobretudo devido às condições de saúde de Saint-Hilaire, só vindo a lume em I830. Para que a tarefa fosse realizada, ele se reportaria às anotações de seu diário pessoal, tendo sempre como compromisso a observação.

Chaque jour, j'écrivais un journal détaillé de ce qui s'offrait à mes regards, etj'y consignais, autant que le permettait mes faibles connaissances, tout ce qui pouvait contribuer à donner une idée exacte des pays que je parcourrais. C'est de ce journal, écrit sur les lieux, quej'extrais la relation historique dont je commence aujourd'hui la publication. (SAINT-HILAIRE, I847, p. VIII) .

[Todos os dias, eu escrevia um diário detalhado do que se apresentava ao meu olhar e anotava, tanto quanto meu conhecimento limitado permitia, tudo o que pudesse ajudar 
a dar uma ideia exata das terras que eu percorria. É desse diário, escrito no local, que extraio a relação histórica cuja publicação começo hoje.]

Diante de uma obra extensíssima como é a de Saint-Hilaire, realizamos uma escolha, privilegiando a pesquisa sobre a viagem entre Rio de Janeiro, Minas Gerais e Goiás, para abordar um trecho da obra em que o viajante entra em contato com os índios, em Minas Gerais, cujo trajeto inclui regiões menos tematizadas pelos viajantes desse período histórico. Poucos viajantes enfrentaram os vazios do Centro-Oeste antes de Saint-Hilaire. Como o próprio botânico lembra

"Les voyages, a dit Chateaubriand, sont une des sources de l'histoire" (CHATEAUBRIAND, I843, $s / p$.). Aujourd'hui nous puisons des documents précieux pour celle de Rio de Janeiro dans les récits naïfs du véridique Léry, qui, le premier parmi les hommes un peu instruits de notre nation, a visité la côte du Brésil : aucun Français avant moi, n'avait parcouru Minas Geraes, Goyaz, S. Paul, etc. (SAINT-HILAIRE, I847, p. IX).

[“As viagens”, disse Chateaubriand, "são uma das fontes da história”. Hoje colhemos documentos preciosos para a história do Rio de Janeiro nos relatos ingênuos das viagens reais de Léry, que, o primeiro entre os homens um tanto instruídos de nossa nação, visitou a costa do Brasil: nenhum francês antes de mim, tinha percorrido Minas Gerais, Goiás, São Paulo, etc.]

A evocação de Chateaubriand tem por finalidade destacar o pioneirismo de Saint-Hilaire, seu caráter destemido, arriscando-se por terras até então negligenciadas por seus conterrâneos, e defender a ideia de que os relatos de viagem são fontes úteis para a construção do discurso historiográfico. Nesse sentido, validado pela autoridade do romancista romântico, Saint-Hilaire reivindica o mérito de vir a ser, no futuro, o autor de um documento de extrema importância para os brasileiros, uma vez que poderão recorrer aos dados por ele anotados

... si quelques exemplaires de mes relations échappent au temps et à l'oubli, un jour on $y$ verra aussi sur ces vastes provinces, devenues peut-être des empires, des renseignements qui peut-être ne seront pas sans intérêt. On s'étonnera d'apprendre que, là où seront alors des villes riches et peuplées, il n'y eut d'abord qu'une ou deux maisonnettes presque semblables à la hutte du sauvage; qu'où l'air retentira du bruit des marteaux et des machines les plus compliquées on entendait à peine le coassement de quelques batraciens et le chant des oiseaux; quavant les nombreuses plantations de maïs, de manioc, de cannes à sucre et d'arbres fruitiers qui couvriront la terre, elle offrait une végétation brillante mais inutile; à la vue des campagnes sillonnées par des chemins de fer, peut-être même par des véhicules plus puissants que nos locomotives, on sourira en lisant qu'il fut un temps où le voyageur s'estimait heureux, lorsque, dans sa journée, il était parvenu à faire 4 ou 5 lieues. (SAINT-HILAIRE, I847, p. IX-X).

[... se alguns exemplares dos meus relatos escapam ao tempo e ao esquecimento, um dia também veremos lá sobre essas vastas províncias, tornadas talvez impérios, informações que talvez não deixem de ter interesse. Ficaremos surpresos ao saber 
que, lá onde estarão então as cidades ricas e populosas, houvera a princípio apenas uma ou duas casinhas quase semelhantes à cabana do selvagem; que, onde o ar ressoará o som de martelos e das máquinas as mais complicadas, dificilmente se ouvira o coaxar de alguns anfíbios e o chilrear dos pássaros; que, antes das numerosas plantações de milho, mandioca, cana-de-açúcar e árvores frutíferas que cobrirão a terra, ela oferecia uma vegetação brilhante mas inútil; ao ver o campo entrecortado por ferrovias, talvez até por veículos mais potentes que as nossas locomotivas, sorrir-se-á ao ler que houve um tempo em que o viajante se considerava feliz, quando, na sua época, conseguira percorrer 4 ou 5 léguas.]

Inspirado pelas palavras de Chateaubriand, Saint-Hilaire concebe seus escritos de viagem como uma fonte documental importante para que os nativos, desconhecedores de sua história, possam recuperar a memória não apenas do país, mas de sua própria cultura, a memória de sua paisagem. Os brasileiros teriam, então, como tomar consciência de quem são, de suas origens, pela obra de um viajante estrangeiro. Cita, à guisa de comparação, a situação da historiografia europeia, afirmando que sua obra permitirá que o Brasil não conheça tal experiência

Una lacune immense restera toujours dans la géographie botanique de l'Europe ; c'est à peine si nous pouvons former quelques conjectures plausibles sur la nature des plantes qu'ont remplacées nos champs de céréales, nos vignes et nos plantations d'oliviers. J'ai tâché que cette lacune n'existât pas dans l'histoire naturelle du Brésil ; j'ai fait connaître la topographie botanique des divers cantons que j'ai visités, et, lorsqu'un jour la culture les aura envahis, on n’ignorera pas ce que fut leur végétation primitive. (SAINT-HILAIRE, I847, p. XIII-XIV).

[Uma lacuna imensa sempre permanecerá na geografia botânica da Europa; é com dificuldade que podemos fazer algumas conjecturas plausíveis sobre a natureza das plantas que substituíram nossos campos de grãos, vinhas e olivais. Tentei que essa lacuna não existisse na história natural do Brasil; divulguei a topografia botânica das várias regiões que visitei e, quando um dia o cultivo os tiver invadido, não se vai ignorar qual era a sua vegetação primitiva.]

Assim, Saint-Hilaire encarga sua obra de ser palimpsesto, receptáculo e depositária da memória natural do Brasil. Através da leitura de seus escritos, o passado desse país, dessas terras, dessa cultura e desse povo seria passível de ser resgatado. Essa postura implica em deslocar para fora do alcance dos brasileiros a construção de sua própria memória, assumindo, ele, o estrangeiro, o privilégio sobre todo o arcabouço de construção de nossa identidade. Como país, como nação, como paisagem, como natureza.

Ainda nesse mesmo diapasão, seguem as observações quando de sua passagem por Minas Gerais, na região do rio Mucuri. Regina Horta Duarte (2002), em “Olhares estrangeiros. viajantes no vale do rio Mucuri”, ao analisar os relatos de quatro viajantes europeus pela região do rio Mucuri - Maximilian, Tschudi, Avé-Lallemand e Saint-Hilaire -, constata que todos têm como temas principais de seus escritos: o indígena, a mata, a colonização e as condições de ocupação do território. A forma 
como Saint-Hilaire entende a relação entre os colonizadores e os índios revela uma visão ambígua do indígena, mas que o mantém na posição de barbárie, vivendo num mundo de caos e desordem, a mata.

Saint-Hilaire dedicou extensas passagens de seus relatos aos botocudos, sem disfarçar a imensa aversão que sentia por eles. [...] Esse viajante enfatiza o aspecto bárbaro da linguagem e sua pronúncia [...] Se não lhes negou completamente nem condição humana, nem o caráter ritual de sua hipotética antropofagia, o distinto botânico caracterizou os botocudos como raça absolutamente inferior, "condenados a uma espécie de infância perpétua” e a uma inexorável extinção. Seres desgraçados, eram dignos apenas de compaixão. (DUARTE, 2002, p. 276).

Assim como o índio é percebido de forma ambivalente, humano, mas inferior e bárbaro por sua pronúncia gutural, "produzindo estrondos de voz que surpreendem quando a eles não se está acostumado" (apud DUARTE, 2002, p. 276), também, num pensamento analógico, Saint-Hilaire descreve a mata de forma ambígua. Se o viajante chama a atenção para a riqueza das terras do Brasil, para a nação promissora em que pode vir a se tornar e projeta sobre esse lugar a possibilidade de vir a receber europeus para explorarem suas potencialidades, desenvolverem a indústria francesa, revelando o olhar utilitário sobre a natureza tropical,

Il est peu de pays qui offrent autant de ressources que le Brésil, et qui soient appelés à jouer dans la politique un rôle aussi brillant; ses montagnes recèlent dans leur sein des métaux précieux, ses rivières couvrent de leurs eaux des diamants et des pierreries; le sucre et le froment, la vigne et le café, les arbres fruitiers de l'Europe et ceux de l'Inde, sont cultivés à la fois sur son territoire fertile; ses immenses solitudes pourraient recevoir d'innombrables colons, et ses ports rassurent d'importants débouchés aux produits de notre sol et de notre industrie. Cependant, malgré les utiles travaux de quelques écrivains dignes d'éloges, cette magnifique contrée est encore bien loin d'être connue. (SAINT-HILAIRE, I847, p. VII).

[Poucos países oferecem tantos recursos quanto o Brasil e que são chamados a desempenhar um papel tão brilhante na política; suas montanhas guardam metais preciosos em seu seio, seus rios cobrem diamantes e pedras preciosas com suas águas; o açúcar e o trigo, a videira e o café, as árvores frutíferas da Europa e as da Índia, são cultivadas em seu fértil território; seus imensos vazios poderiam receber inúmeros colonos, e seus portos asseguram importantes escoamentos para os produtos de nosso solo e de nossa indústria. No entanto, apesar do útil trabalho de alguns escritores louváveis, este magnífico país ainda está longe de ser conhecido.]

seu relato também constrói, à medida que coleta os exemplares de vegetais, animais e minerais para enviar às coleções dos museus da França, um espaço que demanda a ordem e a catalogação. Ou seja, assim como o relato de viagem viria para salvaguardar a memória da natureza, a ciência viria ordenar o caos da floresta. Se os olhos de Saint-Hilaire refletem o maravilhamento diante da riqueza de recursos 
e da variedade de espécimens da natureza tropical, eles também a imobilizam, para poderem dominá-la com as etiquetas e a classificação de Linée, que, já em I735, em seu O sistema da natureza, afirmava que "o fio de Ariadne em Botânica é a classificação, sem a qual só existe o caos" (LINNÉ, 20Io, s. p. apud PRATT, I999, p. 3I). A afirmação de Linné tem implícita a ideia de que os cientistas seriam comparáveis, num certo sentido, a Deus, uma vez que, a partir de um sistema estruturado pela linguagem, organizariam o caos. Isso está na base do discurso colonialista, mas é só um lado da questão; afinal, a ciência permitiu ter acesso a universos desconhecidos.

A forma de organizar o caos da natureza tropical, domando a mata e submetendo-a à organização racional do cientificismo do século XIX, desembocaria em duas paisagens: a agricultura e o jardim, recortes da natureza que forneceriam de forma domesticada, organizada, os produtos desejados.

Pelas matas do Jequitinhonha, ponto máximo ao qual chegou Saint-Hilaire, a menos de 200 quilômetros do Mucuri, o viajante imaginou o seu Novo Mundo, como seria sua vida em harmonia com os negros, os índios e a mata.

As matas seriam derrubadas e substituídas por plantações de milho e algodão, além de pomares. Com o fim gradativo da floresta, o sol aqueceria "com seus raios uma terra sobre a qual não brilhava há séculos”. Mandaria vir cabeças de gado, obtendo leite, queijos e manteiga, pois "um trecho de matas várias vezes queimado forneceria gordas pastagens”. [SAINT-HILAIRE, I847, s/p.]. Construiria um engenho de açúcar e uma serralheria. Ao redor da casa, a vista confusa da mata impenetrável daria lugar a um jardim inglês. Os negros trabalhariam em troca de recompensas. Os índios seriam atraídos com víveres e acostumados ao trabalho. (DUARTE, 2002, p. 288).

Assim como os índios seriam retirados de seu estado de barbárie e aprenderiam a linguagem do colonizador, por meio da catequese, também a confusão que a mata imprimia à visão do viajante seria ordenada, organizada, arrumada, dando lugar a um belo jardim inglês, que enfeitaria o entorno da casa, comportadamente. O cenário idílico inclui a escansão do tempo pelas atividades do mundo do trabalho, racional e lógico, e dela necessita.

Conforme demonstramos em nosso artigo, em suas duas partes, apresentamos uma análise da representação do indígena e sua relação com a natureza e o colonizador, explicitando que o tratamento estético dado ao personagem por Alencar e por Denis revela dois projetos bastante distintos. No conto de Ferdinand Denis, ainda que o indígena seja o mestre da floresta e domine o conhecimento da natureza, destacam-se a relação de submissão do índio ao colonizador e como o processo da colonização já naquele momento aniquilava as populações nativas e sua identidade. Já no romance alencariano, o indígena é apresentado como um herói idealizado, respondendo à necessidade de um personagem que resumisse a identidade nacional brasileira na literatura romântica. O relato de viagem de Saint-Hilaire, cujo objetivo é o de informar os europeus das riquezas do Brasil, revela que, apesar de seu autor conhecer o mito fundador do Brasil - uma ilha muito fértil, de um jardim verdejante -, seu entendimento do território é o de servir como fonte de enriquecimento para a 
Europa, em particular para a França, através da domesticação dos índios e dos negros e do controle da natureza, através da ciência.

Para Saint-Hilaire, o Brasil era uma nação promissora cujos textos fundadores de sua história e de sua memória natural seriam preciosamente guardados sob sua proteção e a dos que detinham o conhecimento científico - o poder de, etiquetando, dar nome, nomear, chamar à vida. Brasil, um jardim para a França.

SOBRE A AUTORA

ANA BEATRIZ DEMARCHI BAREL é professora pesquisadora da Universidade Estadual de Goiás (UEG) e integrante do Grupo de Pesquisa BrasilFrança (Grupebraf) do Instituto de Estudos Avançados da Universidade de São Paulo (IEA/USP). anabeatriz.demarchibarel@gmail.com https://orcid.org/oooo-0003-3I40-756X

\section{REFERÊNCIAS}

ALENCAR, José de. Iracema. Rio de Janeiro: Ediouro, s. d.

ALENCAR, José de. Como e porque sou romancista. Campinas: Pontes, I990.

ALENCAR, José de. O guarani. São Paulo: Ática, I992.

BAREL, Ana Beatriz Demarchi. Excès et identités nationales dans le monde lusophone: le cas des mythes fondateurs. In: PENJON, Jacqueline (éd.). Trop c'est trop. Études sur l'excès en littérature. Les Cahiers du CREPAL n. I2, 2006, p. 37-53.

BAREL, Ana Beatriz Demarchi; COSTA, Wilma Peres (org.). Cultura e poder entre o Império e a República (I822-I930). São Paulo: Alameda, 2018.

BRZOZOWSKI, Jerzy. Brasil, terra do mal: o imaginário de horror na literatura de viagens e ficção francesa do século XIX. Revista do CESP, v. 22, n. 30, jan.jun. 2002, p. 295-309.

CHATEAUBRIAND, François-René de. Voyages en Amérique, en France et en Italie. Paris: Ledentu, I834.

DENIS, Ferdinand. Scènes de la nature sous les tropiques, et de leur influence sur la poésie: suivies de Camoens et Jozé Indio. A Paris, chez Louis Janet, I824.

DENIS, Ferdinand. Résumé de l'histoire du Brésil, suivi du Résumé de l'histoire de la Guyane. Paris: Lecointe et Durey, libraires, I826.

DENIS, Ferdinand. Résumé de l'histoire littéraire du Portugal, suivi du résumé de l'histoire littéraire du Brésil. Paris: Lecointe et Durey Libraires, I826a.

DENIS, Ferdinand; TAUNAY, Hippolyte. Le Brésil, ou Histoire, mours, usages et coutumes des habitans de ce royaume; par M. Hippolyte Taunay, correspondant du Musée d’histoire naturelle de Paris, et M. Ferdinand Denis, membre de l'Athenéé des sciences, Belles-Lettres et arts de Paris. Ouvrage orné de nombreuses 
gravures d'après les dessins faits dans le pays par M. H. Taunay. Paris: Nepveu, Passage des Panoramas, n. 26, I822. $6 \mathrm{v}$.

DUARTE, Regina Horta. Olhares estrangeiros. Viajantes no vale do rio Mucuri. Revista Brasileira de História, São Paulo, v. 22, n. 44, 2002, p. 267-288.

DUPUY, Lionel. Les voyages extraordinaires du Jules Verne ou le roman géographique au XIXe siècle. Annales de géographie, 2013/2 n. 690, p. I3I-I5O.

ECKARDT, Isadora. A perspectiva científica da literatura de viagem do século XIX: Auguste de Saint-Hilaire. Estação Literária, Vagão-Volume 4 (2009)I-Ioo, p. 72-85.

FRANÇA, Jean Marcel Carvalho. O historiador globalizado. Folha Mais!, I/9/2002, p. I-6.

GERALDINO, Samuel Mateus Gerencsez. Reflexões sobre o gosto alimentar nos viajantes franceses do século XIX. In: ENCONTRO ESTADUAL DE HISTÓRIA DA ANPUH-SP, 2I., Campinas. Anais..., setembro de 20I2, p. I-8.

GOMES, Rafael Augusto; MIRANDA, Luiz Francisco Albuquerque de. Auguste de Saint-Hilaire e a civilização indígena: conquista ou filantropia. Mosaico, v. 7, n. Io, 20I6, p. I2I-I36.

GONÇALVES, Gláucia Renate; MALLOY, Letícia. Uma visita à literatura de viagem de Auguste de Saint -Hilaire. Revista Colineares, n. I, v. I, jan.jun. 20I4, p. I03-Io6.

HERBÁRIO Virtual de Saint-Hilaire. Disponível em: http://hvsh.cria.org.br. Acesso em: 20 ago. 2020. HERBÁRIO Virtual de Flora e Fungos. Disponível em: https://bit.ly/3ggiJJG. Acesso em: 20 ago. 2020.

HOLANDA, Sérgio Buarque de. Visão do paraíso. São Paulo: Brasiliense, 2002.

KURY, Lorelai. La politique des voyages en France au début du XIXe siècle et la culture scientifique d'Auguste de Saint-Hilaire. In: LAISSUS, Y. (org.). Les naturalistes français en Amérique du Sud. XVIe-XIXe siècles. Paris: CTHS, I995.

LORENZ, Karl M.; PEIXOTO, Maria Inês H. Os itinerários de seis grandes expedições científicas realizadas no Brasil. Ciência e Cultura, v. 32, n. II, novembro de I980, p. I5I7-I525.

MARIUZZO, Patrícia; MELLO, Sueli. Acervos permitem conhecer viajantes. Revista Eletrônica de Jornalismo Científico Com Ciência - SBPC/Labjor, 29/5/20I9, p. I-4.

MOREYRA, Sérgio Paulo. O olho que vê o mundo. Boletim Goiano de Geografia, v. 7-8, n. I-2, jan.-dez. I987-I988, p. I63-I66.

OLIVEIRA, Lucia Lippi. Natureza e identidade: o caso brasileiro. Revista de Ciências Sociais da PUC-Rio, n. 9, ago.-dez. 20II, p. I23-I34.

OLIVEIRA, Maria de Fátima; MELLO, Marcelo de. Cidades do sertão: o olhar de um francês do século XIX .Outros Tempos, v. Io, n. I5, 2013, p. I73-I87.

PEREIRA, Marco Aurélio Monteiro; IEGELSKI, Francine. O paraíso terrestre no Brasil: os campos gerais do Paraná no relato de Auguste de Saint-Hilaire. Revista de História Regional, 7(I), verão 2002, p. 47-72. PESAVENTO, Sandra Jatahy. O mundo como texto: leituras da história e da literatura. História da Educação, ASPHE/FaE/UFPel, Pelotas, 2003, p. 3I-45.

PRATT, Mary Louise. Os olhos do império: relatos de viagem e transculturação. Bauru: Edusc, I999.

RUNDVALT, Darcio. Visconde Taunay: leitor, observador e escritor. Reverberações do pensamento paisagístico de Saint-Hilaire na Viagem Philosophica aos Campos Geraes e ao Sertão de Guarapuava. In: CONGRESSO INTERNACIONAL DE HISTÓRIA DA UNIVERSIDADE ESTADUAL DE MARINGÁ, 6., Anais..., setembro de 2013.

SAINT-HILAIRE, Auguste de. Voyage aux sources du rio S. Francisco et dans la province de Goyaz. Paris: Arthus Bertrand, Libraire-Editeur, I847.

SHORT, Ian; MERRILEES, Brian. Benedeit. Le voyage de Saint Brendan. Conception et illustrations: Domi- 
nique Tixhon. I999. Web-site publication, Coppet, Suisse. Disponível em: http://saintbrendan.d-t-x. com. Acesso em: 20 jun. 2020.

SOUZA, Almir Antonio de. Um viajante no Brasil Joanino: Auguste de Saint-Hilaire, o caminho das tropas, o mato e o campo, e os índios do planalto meridional. Mneme Revista de Humanidades, v. I5, n. 35, jul.-dez. 20I4, p. I37-I65.SPOSITO, Fernanda. Além do sertão: indígenas no Brasil do século XIX. Almanack, n. I6, agosto de 20I7, p. 343-35I.

TORRÃO FILHO, Amílcar. Bibliotheca Mundi: livros de viagem e historiografia brasileira como espelhos da nação. Projeto História, n. 42, junho de 20II, p. III-I4I.

TOUSSAINT-SAMSON, Adèle. Uma parisiense no Brasil. Rio de Janeiro: Capivara, 2003. 